\title{
Impact of the COVID-19 pandemic on the Australian residential aged care facility (RACF) workforce
}

\section{AUTHORS}

NATALIA KRZYZANIAK PhD ${ }^{1}$

ANNA MAE SCOTT PhD 1

MINA BAKHIT PhD ${ }^{1}$

ANN BRYANT ${ }^{1}$

MARIANNE TAYLOR ${ }^{2}$

CHRIS DEL MAR PhD ${ }^{1}$

\section{CORRESPONDING AUTHOR}

NATALIA KRZYZANIAK Institute for Evidence-Based Healthcare, Faculty of Health Sciences and Medicine, Bond University, 14 University Drive, Robina, QLD 4229, Australia. Phone: +61 755954182.

Email: nkrzyzan@bond.edu.au
1 Institute for Evidence-Based Healthcare, Faculty of Health Sciences and Medicine, Bond University, Gold Coast, Queensland, Australia

2 Rosewood Care Group, Leederville, Western Australia

\section{ABSTRACT}

Objective: We conducted a survey to understand the challenges faced by the staff of residential aged care facilities (RACF), during the COVID-19 pandemic.

Background: In the current pandemic, the RACF workforce has been required to work under stressful conditions, with immense mental and physical pressures, resulting in anxiety and stress felt towards their jobs.

Study design and methods: We electronically surveyed both clinical and non-clinical staff at public and private RACFs in Australia in June and August 2020. The survey asked a mix of openended and closed questions about preparedness for the pandemic, information flow, experience with personal protective equipment (PPE), management of suspected COVID cases, restrictions on visitors, and impact on RACF staff personal and home life. Quantitative data were analysed in SPSS; qualitative data using content analysis.

Results: We received 371 responses: 198 from clinical staff and 168 from non-clinical staff. Respondents were between $20-71$ years old, and $87 \%$ were female most commonly from Victoria (28\%) or New South Wales (28\%). The majority (80\%) felt that Australian
RACFs were well-prepared for the pandemic and $87 \%$ agreed that relevant healthcare authorities were contactable for information needed. A total of $37 \%$ reported challenges in estimating and ordering appropriate quantities of protective equipment. Ninety percent of facilities reported screening residents for possible symptoms and $77 \%$ introduced precautions or quarantine measures to protect residents. Most participants (98\%) reported their RACF implemented restrictions on visitor access and $43 \%$ reported unfair or abusive treatment by family or friends of the residents. Commonly reported personal impacts included: workload increase, stress, emotional toll, family issues and fatigue. Support from colleagues as well as training, de-brief sessions and frequent meetings were identified as helpful facilitators during this time.

Conclusion: We identified a wide range of practices and coping strategies among Australian RACFs. Whilst a majority of respondents reported coping well, a large proportion reported struggling both mentally and physically. Factors reported as helpful by the respondents may assist RACFs in planning for future pandemics. 
Implications for research, policy and practice: Understanding the challenges faced by all levels of staff within RACFs may aid decision-makers on a range of different levels - researchers, aged care providers, local/regional/state health departments and national leaders within government to help inform the development of interventions that may help the sector to recover, as well as prepare for potential future outbreaks. Of particular importance, are interventions or initiatives that focus on supporting the physical and mental health of staff i.e. those that prevent or minimise worker fatigue, emotional burnout and stress.

What is already known about the topic?

- Nursing staff in Australian RACFs did not feel prepared for the COVID outbreak in their workplace.

- Early in 2020, RACF nurses experienced a greater overall workload and some had their staff hours reduced by their employers due to financial constraints caused by the outbreak.
What this paper adds

- This paper offers a comprehensive insight into how RACF staff coped both individually and as part of the facility overall during the COVID crisis.

- It identified that a commonly reported source of stress was first-hand verbal abuse from family or friends of residents in response to visitor and lockdown restrictions implemented by the authorities.

- The paper highlighted that whilst the majority of respondents felt that RACFs were well prepared for managing residents during the pandemic, some facilities experienced significant problems with workloads, PPE and human resourcing.

- Furthermore, the survey showed that on an individual level, some staff experienced significant mental and physical stress during the outbreak.

Keywords: nursing homes; homes for the aged; workforce; COVID-19

\section{BACKGROUND}

The COVID-19 pandemic has proven to be a significant challenge for healthcare systems worldwide. ${ }^{1}$ The aged care sector in particular has been affected, with residential aged care facility (RACFs) residents making up $65 \%$ of all COVID related deaths in Australia. ${ }^{2}$ According to the most recent National Aged Care Workforce Census and Survey as many as 220,000 older people live in RACFs across Australia, with a corresponding total workforce of 230,000 of which 154,000 are direct care workers. ${ }^{3}$ Australian RACF staff are at the frontline of the COVID pandemic response, balancing the provision of an appropriate level of care to high-need residents with personal, family, staff, visitor and resident safety.

A report released by the Australian Nursing and Midwifery Federation (ANMF) found that $43 \%$ of nurses surveyed in May 2020 did not feel prepared for an outbreak of COVID in their workplace and nearly a fifth (19\%) indicated their facility had in fact made cuts to staff hours in response to the COVID-19 outbreak. ${ }^{4}$ Respondents were experiencing significantly increased workloads, felt undervalued and unrecognised and were doing their best to adapt to a changing environment. ${ }^{4}$

\section{OBJECTIVE}

Our aim was to understand the impact of the COVID-19 pandemic on the RACF workforce, including clinical, administrative and auxiliary staff. The survey aimed to identify the challenges faced during the COVID-19 pandemic including the level of preparedness to deal with the pandemic, amount of information provided by state and federal health departments, experiences with PPE, as well as impact on workload and personal obligations. This research will assist in determining whether the RACF workforce was adequately supported by the aged care sector during the outbreak of COVID-19 and will also identify areas of practice that would benefit from further attention to better aid and equip the workforce for future pandemics.

\section{STUDY DESIGN AND METHODS}

This study received ethics approval from the Bond University Human Research Ethics Committee (Approval Number: AS200602).

\section{PARTICIPANTS}

We surveyed all members of the RACF workforce, regardless of work status (i.e. full-time/part-time) or roles (clinical/nonclinical). Participants were contacted through the publicly available GEN Aged Care Data website, which generates a list of all registered RACFs in Australia and their corresponding contact details. One email address per facility was listed and surveys were sent to this email address with a request for the receiver to circulate the survey among staff members within their workplace.

A survey was electronically distributed to members of the RACF workforce between June and August 2020. Participants 
were assured of confidentiality and were informed that their responses would be de-identified.

A sample size calculation was performed for survey questions using a margin of error of $5 \%$, a significance level of $5 \%$ and a confidence level of $95 \%$. The target sample size needed was found to be 341 respondents in total.

\section{SURVEY}

The online survey (in SurveyMonkey Inc) was selfadministered by participants. A total of 54 questions were adapted from a previously developed research instrument being used to understand the challenges faced by Austrian GPs during the pandemic. ${ }^{5}$ The majority of questions required answers based on a fixed 'yes/no/not applicable' scale, and were supplemented by open-ended questions. The questions sought information on; how prepared respondents were to deal with the COVID pandemic, how they were dealing with the challenges brought on by the pandemic, what information they received (or did not receive), their experiences with personal protective equipment, impact on workload and impact on personal/home obligations. All questions were pre-coded for data entry. The full survey instrument is provided in Appendix A.

The survey was pre-tested for intelligibility of content and design by four Australian healthcare professionals and researchers.

Reminders were emailed to participants two weeks and one week before the end of the study period. Surveys that were answered by respondents beyond the demographic data were included in the analysis. Incomplete responses were considered as missing values.

\section{DATA ANALYSIS}

Descriptive statistics (percentages, frequencies) were used to analyse quantitative data via the Statistical Package for the Social Sciences (SPSS) Version 22. The Chi-square test was applied to test the association between independent categorical variables (e.g. participant age, role, state, type of RACF) and dependent variables (e.g. PPE use, level of information/training provided, physical and mental impacts etc.). Statistical significance was accepted at a P value of $<0.05$.

Data obtained from open-ended questions relating to challenges and facilitators during the pandemic were analysed following content analysis procedures, using manual inductive coding. ${ }^{6}$ A list of initial codes was created from the data guided by the survey questions. Significant statements were identified from participant responses and were assigned an initial code; new codes were added when data did not fit existing codes. ${ }^{7}$ The codes were then grouped into broader categories with similar content, and these categories were grouped into themes around the study objectives. $^{8}$

\section{RESULTS}

A total of 2,855 surveys were sent out (corresponding to the number of facilities listed on the GEN Aged Care Data website) with 285 bounces. To maximise the potential number of respondents, we asked the receiver of each email to forward the survey to staff members within their facility. An accurate response rate is difficult to ascertain as it is not known how many surveys were forwarded among colleagues within each RACF. The response rate was calculated with the denominator being the number of surveys sent out electronically by researchers. A total of 425 responses were received and of these 371 respondents completed at least 50\% of the survey questions, yielding a response rate of $13 \%$.

\section{TABLE 1: DEMOGRAPHIC CHARACTERISTICS}

\begin{tabular}{|c|c|c|}
\hline Age $(n=350)$ & Range & $20-73$ \\
\hline \multirow[t]{3}{*}{ Gender ( $n=369$ ) } & Female & $320(87 \%)$ \\
\hline & Male & $48(13 \%)$ \\
\hline & Other & $1(0.3 \%)$ \\
\hline \multirow{3}{*}{$\begin{array}{l}\text { Number of } \\
\text { residents in the } \\
\text { RACF where you } \\
\text { are currently } \\
\text { employed } \\
(n=370)\end{array}$} & Fewer than 50 & $98(27 \%)$ \\
\hline & $50-100$ & $179(48 \%)$ \\
\hline & Over 100 & $93(25 \%)$ \\
\hline \multirow{6}{*}{$\begin{array}{l}\text { Type of RACF } \\
(n=368)\end{array}$} & Private-for-profit & $94(26 \%)$ \\
\hline & Religious & $21(6 \%)$ \\
\hline & Community-based & $20(5 \%)$ \\
\hline & Not-for-profit/charitable & $178(48 \%)$ \\
\hline & State and territory government & $49(13 \%)$ \\
\hline & Local government & $6(2 \%)$ \\
\hline \multirow{8}{*}{$\begin{array}{l}\text { Role in the RACF } \\
(n=366)\end{array}$} & Nurse & $160(44 \%)$ \\
\hline & Assistant in nursing (AIN) & $16(4 \%)$ \\
\hline & Other care assistant & $10(3 \%)$ \\
\hline & $\begin{array}{l}\text { Allied health i.e. occupational } \\
\text { therapist, physiotherapist, } \\
\text { pharmacist etc. }\end{array}$ & $12(3 \%)$ \\
\hline & Administrative personnel & $131(36 \%)$ \\
\hline & Quality and compliance staff & $35(10 \%)$ \\
\hline & Cleaning staff & $1(0.3 \%)$ \\
\hline & Kitchen staff & $1(0.3 \%)$ \\
\hline \multirow[t]{8}{*}{ State $(n=369)$} & VIC & $104(28 \%)$ \\
\hline & NSW & $102(28 \%)$ \\
\hline & QLD & 75 (20\%) \\
\hline & WA & 32 (9\%) \\
\hline & TAS & $24(7 \%)$ \\
\hline & SA & $22(6 \%)$ \\
\hline & ACT & $7(2 \%)$ \\
\hline & NT & $3(0.8 \%)$ \\
\hline
\end{tabular}


A total of $87 \%$ of respondents were female, ranging between 20 and 71 years of age. The largest groups of respondents were direct care staff (51\%) and administrative personnel (36\%). Over one-half were from Victoria and New South Wales (28\% each). Respondents were most commonly employed in notfor-profit RACFs (48\%) followed by private-for-profit (26\%) and state and territory government owned facilities (13\%). Just under half (48\%) were employed in mid-sized facilities caring for between 50-100 residents. Table 1 shows the demographic characteristics of respondents.

\section{RACF PREPAREDNESS FOR THE PANDEMIC}

According to $80 \%(n=290 / 365)$ of respondents, at the beginning of the COVID-19 pandemic, their RACFs were wellprepared for the outbreak. When considering the availability and use of PPE, over one-third of respondents indicated that they found it challenging to estimate and order appropriate quantities of PPE for their facility $(37 \%, n=135 / 366)$. However, over half of respondents felt that their RACF had received enough PPE to look after patients appropriately (59\%, n= 219/369). A significantly greater proportion of private-forprofit and state/territory RACFs compared to not-for-profit/ charitable RACFs felt that they had received a sufficient amount of PPE ( $p<0.05)$. Approximately 66\% ( $n=244 / 371)$ of respondents felt that they had enough individual supplies on hand in the event of an outbreak, but the majority of respondents ( $84 \%, \mathrm{n}=312 / 371)$ knew where they could obtain PPE and received sufficient information on how much PPE they needed $(95 \%, n=353 / 371)$. See Appendix B for a response distribution (\%) for all items.

However, there were some concerns about PPE expressed in respondents' qualitative answers, with many stating that PPE was unavailable at some facilities at the beginning of the outbreak and continued to be unavailable in some cases for 10 days, which caused stress around working conditions. Furthermore, it was noted that any suppliers with available PPE had increased prices substantially (Appendix C).

"Initially supplies of PPE were very hard to find and when you could procure it, the price had in most cases tripled." R185

\section{TESTING OF SUSPECTED CASES}

Over half of respondents $(63 \%, n=232 / 368)$ indicated that RACFs had adequate access to testing of residents (either in-house or domiciliary collection) and 81\% felt that an appropriate level of testing for COVID-19 had been undertaken in their facility $(n=281 / 349)$. However, a significantly greater proportion of participants from state/ territory government run RACFs compared to not-for-profit RACFs felt that they had a satisfactory level of access to tests $(\mathrm{p}<0.05)$.

\section{PROVISION OF INFORMATION TO RACF WORKERS}

A total of $92 \%(n=339 / 368)$ of respondents agreed that their facility had received sufficient amounts of information on dealing with suspected cases and 66\% $(n=243 / 368)$ indicated that their facility had received clear instructions from official bodies about the testing of residents. Furthermore, approximately $87 \%(n=322 / 371)$ of respondents agreed that relevant healthcare authorities were easily able to be contacted for further information when needed (see Table 2 for a complete list of the healthcare authorities contacted by the RACF workforce).

\section{TABLE 2. HEALTHCARE AUTHORITIES CONTACTED BY THE RACF WORKFORCE}

\begin{tabular}{|l|l|}
\hline Level of authority & Types of organisations \\
\hline Facility-level & $\begin{array}{l}\text { Management, head office or corporate } \\
\text { offices of aged care facilities, head office } \\
\text { infection control hotline, infection control } \\
\text { nurse and team }\end{array}$ \\
\hline Local level & $\begin{array}{l}\text { GP services, public health units, local health } \\
\text { departments, local disaster management } \\
\text { group (LDMG) }\end{array}$ \\
\hline Regional & $\begin{array}{l}\text { Hospitals and their associated in-reach } \\
\text { teams, ACE - aged care emergency service, } \\
\text { primary health network }\end{array}$ \\
\hline State & $\begin{array}{l}\text { Departments of Health from ACT, NSW, } \\
\text { QLD, SA, VIC and WA }\end{array}$ \\
\hline Federal/national & $\begin{array}{l}\text { Commonwealth Department of Health, } \\
\text { COVID hotline }\end{array}$ \\
\hline Aged care leading \\
bodies & $\begin{array}{l}\text { Aged Care and Community Services } \\
\text { Australia (ACSA), Leading Age Services } \\
\text { Australia (LASA) and the Aged Care Quality } \\
\text { and Safety Commission }\end{array}$ \\
\hline
\end{tabular}

Over 90\% $(n=349 / 370)$ of respondents stated that they had received instruction on how to use personal protective equipment (PPE) and the majority received sufficient information on the type $(95 \%, \mathrm{n}=353 / 371)$ and quantity of PPE $(84 \%, 311 / 371)$ needed. There were no significant differences noted between clinical and non-clinical staff perceptions of each of the questions associated with their individual work experiences ( $\mathrm{p}>0.05)$.

However, some respondents in the open-ended questions noted that they had experienced significant communication issues with certain health authorities. Several were unable to make contact with particular information services, whilst others had received conflicting information from different authoritative bodies. (Appendix C).

"You could not reach the helpline as it was too busy. We were completely on our own.” R43 


\section{CONTROLLING THE SPREAD OF THE PANDEMIC}

To mitigate the risk of an outbreak, most respondents reported that at their facilities, residents were screened for possible symptoms (90\%, $n=316 / 352)$ and approximately $77 \%(n=272 / 353)$ indicated that their facility had introduced precautions or quarantine measures to ensure residents did not come into contact with suspected cases. Under one-third of participants $(30 \%, n=107 / 352)$ identified that their facility experienced difficulties isolating residents with suspected/confirmed COVID due to specific medical conditions including, dementia, short term memory loss or other cognitive impairment conditions, behavioural and wandering issues, as well as facility-based problems including shared rooms and bathrooms and staff shortages. A higher proportion of staff from private-for-profit and religious facilities compared to state/territory RACFs reported difficulties with isolating patients $(\mathrm{p}<0.05)$.

Only $8 \%(n=28 / 349)$ of respondents indicated that their RACF had employed forms of enforced isolation to quarantine residents with suspected or confirmed COVID-19. Respondents listed the following types of enforced isolation that were used: chemical restraint $(n=1)$, locked doors $(n=1)$, transfer to other wings or acute hospitals $(n=2)$, use of a barn door $(n=2), 1: 1$ nursing $(n=2)$, and isolation rooms $(n=6)$.

Several respondents, from open-ended questions, noted that extra staff were required to help manage patients with suspected COVID-19 who also had dementia or cognitive impairments as a 'special' on a 1:1 basis.

"Residents with dementia were very difficult to isolate and staff were constantly redirecting. At times, a 1 to 1 staff was required." R126

"Limited single rooms in our facility. Difficulty isolating wandering residents--extra staff put on to help manage." R4

\section{PROTECTION OF RACF STAFF AND DECREASED NUMBER OF POTENTIAL CONTACTS}

Most respondents (90\%) felt that facility staff followed appropriate procedures when experiencing symptoms of COVID-19 (90\%) and only 2\% reported that staff had been sent home early due to the lack of PPE in the facility. Approximately $43 \%$ of respondents $(n=150 / 352)$ indicated that at least one staff member at their facility who identified as being at an increased risk of COVID-19 (as they belonged to a vulnerable group e.g. pregnant women, older employees) ceased working during the outbreak.
The majority of respondents noted that their facilities had imposed infection control procedures (99\%, $\mathrm{n}=348 / 352)$ and restrictions on visitor access $(98 \%, n=344 / 351)$. In response to these restrictions, $43 \%(n=150 / 351)$ of respondents reported that they had been unfairly or abusively treated by family or friends. Subsequently, approximately $62 \%(n=217 / 351)$ of respondents highlighted that their facility had received official complaints from family or friends of friends because of issues related to the pandemic. In comparison, only 15\% (n $=51 / 352)$ of respondents felt that they had been mistreated or abused by residents themselves. Interestingly, a significantly higher proportion of respondents from private-for-profit and not-for-profit facilities compared to state/territory government-run facilities reported experiencing pandemicrelated abuse from family members/visitors ( $\mathrm{p}<0.05)$.

The implementation of visitor restrictions, as well as restrictions limiting residents' regular activities within and outside of the facility (including exercise and shopping trips) had a significant impact on resident's emotional wellbeingparticularly for residents with cognitive impairments and for palliative patients. The inability for these residents to be with their family during their time of need was very distressing for all parties involved - residents, family/friends and staff.

"I noticed that some residents with dementia or on low incomes, or with diagnosed mental health conditions have become extremely depressed throughout this period of lock down. The sense of disconnection from family and friends appears to have increased and the sense of self-worth has declined and is expressed in their unkempt appearances. Some have found it difficult to adjust to home-based activities and a new set of rules. Some have missed being connected with sporting and physical activities. A small group of carers experienced significant grief and anger issues at having restricted access to their partners. They experienced significant grief and a sense of loss." R146 


\section{FACILITIES WITH POSITIVE COVID CASES}

A total of two respondents from two different facilities reported that a resident or staff member at their workplace had received a positive COVID-19 result: a private-for-profit and a not-for-profit/charitable facility. Similar responses were obtained from both respondents for most questions. Both had been instructed how to use PPE, had received sufficient information on the type of PPE needed, where to source PPE and how to deal with suspected cases. However, there were some differences noted in relation to testing and PPE supplies. The respondent from the not-for-profit facility felt that they did not receive enough information on how much PPE they needed and also observed that the facility did not have enough PPE supplies on hand to look after residents appropriately. Furthermore, this respondent also reported that they did not receive enough information on the testing of residents, or have satisfactory access to testing, and overall judged the facility as being unprepared for the pandemic. In comparison the private-for-profit respondent was satisfied with each of these measures. Both respondents noted an increase in workloads during the pandemic, with the not-forprofit reporting a 'very high' and the private-for-profit a 'high' workload.

\section{PERCEPTION OF PERSONAL RISK}

The majority of respondents were not concerned that they would contract COVID-19 from residents $(87 \%, \mathrm{n}=$ 304/349). A significantly higher proportion of AINs than registered nurses were afraid of contracting COVID-19 from a resident $(\mathrm{p}<0.05)$. Half of respondents were worried about unknowingly infecting residents $(52 \%, \mathrm{n}=181 / 348)$, and over one-quarter were concerned about infecting close family or friends $(27 \%, \mathrm{n}=95 / 349)$.

\section{PERSONAL IMPACT}

Overall, 63\% ( $n=219 / 349)$ of respondents reported that they had suffered from work-related stress resulting from the COVID-19 outbreak. Importantly, over half (53\%, n = 185/347) had been offered mental health support from their workplace. However, $28 \%(n=97 / 349)$ indicated that they were concerned about the continuing impact of the pandemic on their mental health. A significantly higher proportion of registered nurses than other care assistants felt that they had experienced additional work-related stress because of COVID-19 $(\mathrm{p}<0.05)$. See Table 3 for the list of reported personal impacts as a result of the pandemic.
TABLE 3. PERSONAL IMPACT OF PANDEMIC ON RACF WORKFORCE

\begin{tabular}{|l|r|}
\hline I suffered from one or more of these because of the pandemic: \\
\hline Burnout & $123(33 \%)$ \\
\hline Anxiety & $116(31 \%)$ \\
\hline Insomnia & $98(26 \%)$ \\
\hline Depression & $21(6 \%)$ \\
\hline Grief & $11(3 \%)$ \\
\hline
\end{tabular}

Approximately 51\% ( $n=172 / 335)$ of respondents felt that they had experienced a 'very high' workload since the outbreak of the pandemic in March 2020, 31\% ( $n=103 / 335)$ felt that it was 'high', and 16\% ( $n=53 / 335)$ felt that it was 'moderate'. A higher proportion of non-clinical (comprising administrative, quality and compliance, kitchen and cleaning staff) than clinical staff felt that they had faced a 'very high' workload since the beginning of the pandemic $(p<0.05)$. Furthermore, a higher proportion of respondents from private-for-profit and not-for profit/charitable facilities in comparison to state and territory government facilities reported a 'very high' workload $(\mathrm{p}<0.05)$. A significantly higher proportion of AINs compared to registered nurses reported that they looked after more residents because other staff were less available $(\mathrm{p}<0.05)$.

In their qualitative answers, several respondents also noted that keeping up with the directions from the government and implementing their recommendations was timeconsuming. Workload increases were particularly associated with monitoring and documentation processes, screening staff and visitors, and providing additional communication and support to residents and their families. Some respondents were working $12+$ hour days and taking work home with them to catch up with the load. (Appendix C)

"Work-related stress due to daily new updates which had to be implemented immediately and additional workload due to COVID-19 restrictions and safety measures." R158

Human resourcing was highlighted by respondents as an important challenge during the outbreak. Staff cuts and absences due to sickness, home-based obligations (i.e. homeschooling children) and quarantine after suspected COVID-19 meant that some RACFs were struggling with the workload and were unable to source more staff because of financial issues or a lack of available staff. 


\section{QUALITATIVE ANALYSIS - CHALLENGES, FACILITATORS, AND RECOMMENDATIONS FOR CHANGE}

A summary of the challenges perceived by respondents during the pandemic is presented in Table 4. Respondents also identified several factors perceived as being important support structures for the workforce during the outbreak, which are summarised in Table 5 .

\section{TABLE 4. CHALLENGES REPORTED BY RACF WORKERS DURING THE PANDEMIC}

\begin{tabular}{|c|c|c|c|}
\hline $\begin{array}{l}\text { Overall } \\
\text { theme }\end{array}$ & Subtheme & Description & Supporting quotations \\
\hline \multirow[t]{4}{*}{$\begin{array}{l}\text { Personal } \\
\text { challenges }\end{array}$} & $\begin{array}{l}\text { Burden of } \\
\text { providing high- } \\
\text { level emotional } \\
\text { support }\end{array}$ & $\begin{array}{l}\text { The isolation of residents from their families and } \\
\text { friends, in some instances, led to staff needing to } \\
\text { provide additional high-level emotional support } \\
\text { to meet residents needs as well as being primary } \\
\text { caregivers. }\end{array}$ & $\begin{array}{l}\text { "Whilst residents were isolated to the facility, } \\
\text { hence not having family and friends visiting to } \\
\text { support them, I became their only emotional and } \\
\text { spiritual support. I felt like a 'sponge' absorbing } \\
\text { all their anxieties, sadness and grief. Although I } \\
\text { endeavoured not to bring this home to my family, } \\
\text { it did have an impact. I would spend time readying } \\
\text { and preparing myself mentally to enter the facility } \\
\text { each morning to ensure I had a 'happy face' and the } \\
\text { same again at the end of the day prior to entering } \\
\text { my home. I found myself waking throughout the } \\
\text { night and waking early thinking of ways to bolster } \\
\text { the residents and staff." R249 }\end{array}$ \\
\hline & $\begin{array}{l}\text { Managing family } \\
\text { responsibilities }\end{array}$ & $\begin{array}{l}\text { Due to long work hours, respondents consequently } \\
\text { experienced challenges around managing family } \\
\text { responsibilities. Some respondents noted difficulties } \\
\text { with arranging childcare whilst they were working. } \\
\text { Others stated that, overall, they spent significantly } \\
\text { less time at home with their own families, which was } \\
\text { particularly difficult for families with children who } \\
\text { were home-schooled for a period of time. }\end{array}$ & $\begin{array}{l}\text { - "My biggest challenge was organising suitable care } \\
\text { for my young children." R289 } \\
\text { - "Finding the time to work and home school with a } \\
\text { senior and primary child at home." R74 }\end{array}$ \\
\hline & $\begin{array}{l}\text { Fatigue/ } \\
\text { exhaustion }\end{array}$ & $\begin{array}{l}\text { Respondents reported feeling physically exhausted } \\
\text { due to increased workloads and longer workdays. } \\
\text { Respondents reported not being able to take any } \\
\text { leave or having to come to work as a necessity due } \\
\text { to other family members losing their jobs during this } \\
\text { time, leading to fatigue. }\end{array}$ & $\begin{array}{l}\text { "The whole thing has been exhausting and } \\
\text { extremely stressful. We had an exposure in the } \\
\text { nursing home and that was the worst two weeks of } \\
\text { my career. No-one contracted COVID-19 but I was } \\
\text { working over } 12 \text { hours a day for the two weeks to } \\
\text { ensure everyone was ok." R23 }\end{array}$ \\
\hline & Financial issues & $\begin{array}{l}\text { Several respondents reported losing work hours and } \\
\text { subsequently were experiencing financial issues. }\end{array}$ & $\begin{array}{l}\text { - "As an Agency nurse I was out of work for eight } \\
\text { weeks and this impacted on my financial status." } \\
\text { R379 } \\
\text { - "I lost work hours - to give to casual staff." R277 }\end{array}$ \\
\hline \multirow[t]{2}{*}{$\begin{array}{l}\text { Work- } \\
\text { related } \\
\text { challenges }\end{array}$} & $\begin{array}{l}\text { Pressures related } \\
\text { to management } \\
\text { roles }\end{array}$ & $\begin{array}{l}\text { Respondents in managerial and CEO roles reported } \\
\text { experiencing extra stress, increased workloads and } \\
\text { work hours leading to issues with sleeping and } \\
\text { burnout. Some felt that they were not provided } \\
\text { with adequate support or assistance from their own } \\
\text { facilities or the government during this time. }\end{array}$ & $\begin{array}{l}\text { - "Working in management role give me extra } \\
\text { pressure and get to the level of burnout. No extra } \\
\text { funding even make it harder to run the place." R93 } \\
\text { - "As a manager I was told to cut staff at the peak of } \\
\text { the pandemic. This created extra stress so I took } \\
\text { on extra work hours to reduce stress on others and } \\
\text { this has led to burnout and stress." R244 } \\
\text { - "As the facility manager I had some sleepless } \\
\text { nights concerned about how I could keep my } \\
\text { residents and staff safe with the issue of getting } \\
\text { PPE." R315 }\end{array}$ \\
\hline & Visitor abuse & $\begin{array}{l}\text { Experiencing first-hand verbal abuse from family } \\
\text { or friends of residents in response to visitor and } \\
\text { lockdown restrictions implemented by the facilities } \\
\text { and authorities. Restrictions relating to mandatory } \\
\text { temperature checking, flu vaccination, PPE use, } \\
\text { and as the virus spread, subsequent closures of } \\
\text { facilities, lead to increases in angry and aggressive } \\
\text { confrontations as well as documented complaints. }\end{array}$ & $\begin{array}{l}\text { - "Abusive families, demanding proof of legislation } \\
\text { supporting restrictions." R50 } \\
\text { - "Several relatives took out their frustrations on the } \\
\text { Admin team, making work life a little difficult to } \\
\text { not take home and think about." R38 } \\
\text { - "The anger and fear of families during this time was } \\
\text { particularly distressing and time consuming and } \\
\text { was often generated by the conflicting statements } \\
\text { coming from State and Federal governments." R315 }\end{array}$ \\
\hline
\end{tabular}


TABLE 4. CHALLENGES REPORTED BY RACF WORKERS DURING THE PANDEMIC (CONTINUED)

\begin{tabular}{|c|c|c|c|}
\hline $\begin{array}{l}\text { Overall } \\
\text { theme }\end{array}$ & Subtheme & Description & Supporting quotations \\
\hline \multirow[t]{3}{*}{$\begin{array}{l}\text { Work- } \\
\text { related } \\
\text { challenges }\end{array}$} & $\begin{array}{l}\text { Keeping up } \\
\text { with policy and } \\
\text { practice changes }\end{array}$ & $\begin{array}{l}\text { Respondents found it particularly challenging to } \\
\text { keep up with the perceived overload of information } \\
\text { that was provided by authorities. Often, this } \\
\text { information was found to be conflicting between } \\
\text { different authoritative bodies, leading to confusion. } \\
\text { Finding consistency in the policy and procedure } \\
\text { changes requested by the government, relaying this } \\
\text { information to staff as well as residents and their } \\
\text { families and implementing the correct changes and } \\
\text { restrictions was felt to be particularly challenging. }\end{array}$ & $\begin{array}{l}\text { - "Lack of clear instructions from government/Health } \\
\text { department." R386 } \\
\text { - "Keeping staff, residents and families informed. I } \\
\text { received multiple emails and newsletters each day } \\
\text { from various government bodies and agencies. } \\
\text { Each need to be read and information passed to } \\
\text { relevant areas." R185 }\end{array}$ \\
\hline & $\begin{array}{l}\text { Feeling } \\
\text { undervalued by } \\
\text { the community }\end{array}$ & $\begin{array}{l}\text { Feeling unappreciated and unsupported by the } \\
\text { media, general public, government and by the } \\
\text { board of directors of their own facilities. The } \\
\text { media in particular was highlighted as a source of } \\
\text { discomfort for many, due to reports 'demonising' } \\
\text { RACFs, 'sensationalising' issues and 'over-stimulating' } \\
\text { the public, when the general feeling was that } \\
\text { the workforce was doing their best to follow } \\
\text { procedures and policies imposed by the government. } \\
\text { Respondents stated staff morale was already low, } \\
\text { and the criticism and lack of appreciation was a } \\
\text { difficult aspect of the job. }\end{array}$ & $\begin{array}{l}\text { - "I feel unappreciated by my government and by the } \\
\text { community who's loved one's we have tried to keep } \\
\text { safe. We received constant criticism." R357 } \\
\text { - "Aged care facilities have been demonised in the } \\
\text { press with staff leaving because of the pressure } \\
\text { and negative attitude from the government and } \\
\text { press. We do a fantastic job with one of the lowest } \\
\text { wages in healthcare but are constantly being } \\
\text { asked to do more with less. Aged care is burning } \\
\text { out staff to not return to the sector." R8 }\end{array}$ \\
\hline & $\begin{array}{l}\text { Resourcing } \\
\text { issues }\end{array}$ & $\begin{array}{l}\text { Some respondents experienced issues with the } \\
\text { telephone/pager and technology systems in their } \\
\text { RACFs. In order to connect residents with the } \\
\text { families, staff members were having to walk to and } \\
\text { from rooms with portable phones, impacting on } \\
\text { workloads and fatigue. } \\
\text { Owners of RACF facilities also reported difficulties } \\
\text { in running their businesses due to large price hikes } \\
\text { for PPE and consumables, and a lack of funding or } \\
\text { support from government. }\end{array}$ & $\begin{array}{l}\text { - "Lack of consumables available PPE, continence } \\
\text { products, stoma and catheter products." R164 } \\
\text { - "Staffing cuts by owner: inability to replace sick } \\
\text { Team members: Lack of casual pool RNs as they } \\
\text { worked in Hospital environment and had to self- } \\
\text { isolate due to cluster in acute care setting." R308 } \\
\text { - "Not enough funding to support the amount of } \\
\text { extra work required e.g. paperwork, policies and } \\
\text { procedures, etc." R386 }\end{array}$ \\
\hline
\end{tabular}

TABLE 5. FACILITATORS REPORTED BY RACF WORKERS DURING THE PANDEMIC

\begin{tabular}{|c|c|c|}
\hline Theme & Description & Supporting quotations \\
\hline $\begin{array}{l}\text { Support from team and } \\
\text { management }\end{array}$ & $\begin{array}{l}\text { Support from managers and head office was } \\
\text { acknowledged as being important and working } \\
\text { together as a team was perceived as being very } \\
\text { helpful. }\end{array}$ & $\begin{array}{l}\text { - "I have been very well supported by my manager } \\
\text { and clinical leader with daily updates with any } \\
\text { changes and ongoing restrictions." R30 } \\
\text { - "Support was given by management to all staff to } \\
\text { deal with these matters." R50 } \\
\text { "The concerted support from management team } \\
\text { of the service as well as the inherent cooperation } \\
\text { among staff members. Strong teamwork and can- } \\
\text { do attitude. Willingness to put in the extra hours } \\
\text { to ensure that residents care needs are thoroughly } \\
\text { met." R56 }\end{array}$ \\
\hline Training and frequent meetings & $\begin{array}{l}\text { Training sessions, de-briefing sessions in the form of } \\
\text { daily meetings or counselling sessions, or walks and } \\
\text { informal chats and simply thanking staff for their } \\
\text { work was observed as being an effective morale } \\
\text { booster and helped staff regain their confidence in } \\
\text { their roles. }\end{array}$ & $\begin{array}{l}\text { "We set up a staff action team and this promoted } \\
\text { strength and support and all staff were included } \\
\text { and their concerns and ideas actions which showed } \\
\text { respect and we were listening. Staff and residents } \\
\text { banded together, daily morning tea updates, } \\
\text { afternoon tea updates, their ideas and voices also } \\
\text { heard. Residents also were coming up with novel } \\
\text { ways to beat COVID-19." R213 } \\
\text { - "Updating and training staff on a regular and timely } \\
\text { basis, making sure infection control measures are } \\
\text { taken timely and appropriately." R67 } \\
\text { "Constantly reinforcing and thanking staff for the } \\
\text { great job they are doing." R45 }\end{array}$ \\
\hline
\end{tabular}


TABLE 6. RECOMMENDATIONS FOR FUTURE CHANGES

\begin{tabular}{|c|c|c|}
\hline Theme & Description & Supporting quotations \\
\hline $\begin{array}{l}\text { Access to resources } \\
\text { and embracing } \\
\text { technology }\end{array}$ & $\begin{array}{l}\text { Adequate supplies of PPE, and access to portable phone } \\
\text { and paging systems, and technological devices such as } \\
\text { large screen iPads and tablets were viewed as essential } \\
\text { elements for facilitating satisfactory working conditions } \\
\text { during the outbreak. }\end{array}$ & $\begin{array}{l}\text { - "PPE available from suppliers." R28 } \\
\text { - "Having access to basic consumables and infection } \\
\text { control needs." R217 } \\
\text { - "Additional iPads and portable phones were provided to } \\
\text { facilitate facetime/over the phone communication with } \\
\text { families." R205 }\end{array}$ \\
\hline Staffing & $\begin{array}{l}\text { Adequate staffing of RACFs was perceived as being } \\
\text { of particular importance with additional staff required } \\
\text { to manage the communication, documentation and } \\
\text { implementation of restrictions requested by authorities, } \\
\text { as well as cleaning staff, and nursing staff to manage } \\
\text { workloads. }\end{array}$ & $\begin{array}{l}\text { - "More staff need to be employed." R90 } \\
\text { - "An increase in staffing levels to share the load." R249 } \\
\text { - "More hours for staff so someone could have been } \\
\text { allocated to the monitoring of temperatures and } \\
\text { wellbeing of staff and consumers and visitors." R165 }\end{array}$ \\
\hline $\begin{array}{l}\text { Supportive media } \\
\text { coverage }\end{array}$ & $\begin{array}{l}\text { Respondents felt that there was a need for more positive } \\
\text { media coverage of RACFs and the workforce. }\end{array}$ & $\begin{array}{l}\text { - "Continual support for aged care restrictions/visits } \\
\text { through advertising and media." R16 } \\
\text { - "Greater media publicity explaining the restrictions that } \\
\text { were developed were at the instruction of federal and } \\
\text { state government and not the facility." R311 } \\
\text { - "Less negative news about aged care from the media." } \\
\text { R29 }\end{array}$ \\
\hline $\begin{array}{l}\text { Teaching the public } \\
\text { on proper face mask } \\
\text { use }\end{array}$ & $\begin{array}{l}\text { To assist visitors with the implemented restrictions, } \\
\text { respondents suggested providing more training on } \\
\text { appropriate infection control procedures. }\end{array}$ & $\begin{array}{l}\text { - "Educating families about infection control, how to put } \\
\text { on masks and proper disposal." R177 }\end{array}$ \\
\hline $\begin{array}{l}\text { Support from the } \\
\text { government as well } \\
\text { as industry bodies } \\
\text { and advocacy groups }\end{array}$ & $\begin{array}{l}\text { Government support in the form of funding to help with } \\
\text { resourcing (both staff and PPE) as well as physical human } \\
\text { resource assistance. Several respondents highlighted a } \\
\text { need for an RACF-specific point of contact at state and } \\
\text { federal level from whom staff would be able to request } \\
\text { more information and ask questions. } \\
\text { Furthermore, respondents also highlighted a need for } \\
\text { more verbal support from key political leaders, who they } \\
\text { felt up until now had not been good advocates for the } \\
\text { RACF workforce. }\end{array}$ & $\begin{array}{l}\text { - "To be supported by government officials to protect } \\
\text { our vulnerable elderly during the pandemic instead } \\
\text { of telling us that they will 'name and shame' those } \\
\text { facilities for not letting in visitors." R59 } \\
\text { - "Support from the federal government instead of } \\
\text { shaming and blaming." R8 } \\
\text { - "Greater financial assistance and recognition. } \\
\text { Recognition that all residential care staff are front line } \\
\text { workers - catering, cleaning, laundry, administration, } \\
\text { finance, lifestyle management..." R129 }\end{array}$ \\
\hline
\end{tabular}

\section{DISCUSSION}

Responses for 371 clinical and non-clinical staff from Australian RACFs provide an important insight into how the RACF workforce has managed during the COVID-19 outbreak and clearly demonstrates how widely practices and coping strategies differ among Australian RACFs.

The most commonly reported problems faced by respondents related to issues with family members and friends of residents, a lack of clear messaging from the government about appropriate protocols, a lack of PPE at the beginning of the pandemic as well as an increase in staff workloads resulting in emotional and physical fatigue. Several studies have reported similar results, with RACF staff worldwide experiencing challenges including: burnout due to high workloads, emotional exhaustion, fear of contagion, exposure to high degrees of suffering, PPE shortages, and lack of testing. ${ }^{9-11}$ Despite these negative working conditions, one Spanish study reported that nursing home staff had very high levels of professional satisfaction during the COVID-19 crisis. ${ }^{9}$ However, as the RACF workforce was already under pressure and vulnerable pre-COVID-19, there is a need to implement practical and effective support strategies to ensure their short and long term wellbeing as this pandemic continues to evolve.

Overall, a significantly higher proportion of respondents from non-profit RACFs reported experiencing family/ visitor abuse, as well as issues with adequate access to PPE and COVID testing. This was also reflected in the response from the facility that had a confirmed COVID-19 case. The respondent from the not-for-profit facility reported issues with PPE supply and testing, compared to a privatefor-profit respondent who was satisfied with the level of facility preparedness. Furthermore, a higher proportion of respondents from private-for-profit and not-for-profit facilities also reported experiencing a 'very high' workload since the pandemic outbreak. This indicates that state/ territory run RACFs seemed to manage better during the outbreak and were better resourced. This may be attributed to staffing and organisational differences across facilities. A study by the Royal Commission noted that state-run RACFs in Victoria and Queensland have minimum resident to staff ratios, however these requirements did not apply to the private sector. ${ }^{12}$ In this same report, government-run facilities 
had the best average results for 31 indicators across four domains, including clinical, workforce, resident feedback and restraints, assaults and missing resident indicators. ${ }^{12}$ As such, these inherent differences may have also had an impact on the COVID response efforts, based on facility type.

Interestingly, there were no significant differences noted between clinical and non-clinical staff perceptions for the majority of questions asked ( $p>0.05)$. Only one major difference was found with a higher proportion of nonclinical staff reporting a 'very high' workload compared to clinical staff. This may be attributed to the significant administrative burden that RACFs have been faced with including understanding, implementing and documenting often conflicting recommendations from authoritative bodies around infection control measures and visitor restrictions. A US-based study by White et.al. confirmed these findings, highlighting that administrative roles continued to grow with the pandemic and involved coordinating data systems for federal reporting requirements, maintaining communication with residents' families, managing staff shortages and coordinating appropriate responses to state and national policies. ${ }^{11}$

The changes to clinical staff workloads has also been significant, as described in qualitative responses. Direct care staff were also filling multiple roles, particularly as emotional-based supports, to ensure resident quality of life during periods of enforced visitor restrictions and dealing with subsequent pressures from residents' family and friends. ${ }^{13}$

It is important to note that there were observed discrepancies among participant qualitative and quantitative responses. Most respondents indicated positive responses to quantitative questions, however the majority of answers provided to the corresponding qualitative questions highlighted significant issues. The motivating factors driving these discrepancies are unclear. The differences may indicate that respondents who did experience issues during the pandemic were most vocal and expressive than other respondents in the qualitative questions. Another potential factor may be that respondents who responded negatively in their qualitative responses may not feel that they can provide this feedback directly within their organisation, and feel more comfortable expressing their experiences and opinions anonymously through this study. Overall, a small proportion of respondents from the whole survey answered the openended questions, and as such the opinions expressed here cannot be generalised to the whole population.

It is also important to consider that whilst the majority of respondents indicated that they had managed well in working during the outbreak, a large proportion felt that they had struggled both mentally and physically. This indicates that there is a need for supportive interventions to be implemented and maintained. Measures, such as having debrief sessions after the shift or having a close colleague to speak to was appreciated by staff. These results are reflected in the preliminary findings from the Impact of COVID-19 on the Nursing and Midwifery workforce (ICON) study; a UK-based survey. ${ }^{14}$ The UK findings indicated that there was a need for the provision of interventions that supported the psychological and physical needs of the workforce both during and after the pandemic. As the pandemic carries on, with continued waves, it is important for future planning to address these concerns to prevent burnout and mental health issues. ${ }^{14}$

A strength of this study is its inclusion of both clinical and non-clinical staff, which allows for a fuller insight into the impact of COVID on the RACF workforce. The surveying of non-clinical staff in particular is not as common, and as such the study adds an additional perspective to the management of RACFs during the pandemic. Another strength is that the study exceeded the calculated sample size, with a total of 371 respondents.

\section{LIMITATION OF THE STUDY}

The study findings are subject to some limitations. First, the extremely low response rate is a clear limitation.

The surveys were distributed electronically to the email address listed on the GEN database. The authors assume that most of these email addresses were directed to an administrative team/leader. This may have had an impact on response rates as well as the types of responses obtained as the study relied on the email being forwarded among staff within each facility.

The assessment of RACF preparedness and self-competence during the pandemic is highly prone to self-report bias. Therefore, the findings may be overestimated due to the potential for social desirability bias.

The survey was completed by a proportion of the RACF workforce in Australia (approximately 0.1\% of the total potential workforce), and as such may not be representative of this population. The majority of direct care respondents were registered nurses, with AINs and care assistants making up 7\% of respondents. Further analysis was done to compare registered nurse responses to AIN and other care assistants. Overall, there were no statistically significant differences between groups for the majority of questions, with similar responses for PPE training and perceived preparedness. However, a higher proportion of AINs than registered nurses felt that they looked after more residents than other staff during the pandemic and were also worried about catching COVID-19 from a resident. In the RACF environment, AINs and personal care workers tend to have the highest level of one-to-one contact with patients (i.e. bathing, dressing and meal time) and their experiences may differ to those of registered nursing staff, whose roles are more focussed on clinical duties including medication administration, nursing 
care and leading/overseeing infection control and emergency response procedures. ${ }^{1516}$ Therefore, the results obtained from the clinical care group may not be representative of the AIN and personal care assistant population. Due to these limitations results should be interpreted with caution.

\section{CONCLUSION}

We identified a wide range of practices and coping strategies among Australian RACFs. Whilst a majority of respondents reported coping well, a large proportion reported struggling both mentally and physically. Respondents from nonprofit RACFs in particular reported experiencing a higher proportion of issues with access to PPE and testing, and very high workloads in comparison to state/territory run facilities. Factors reported as helpful by the respondents may assist RACFs in planning for future pandemics.

\section{IMPLICATIONS FOR RESEARCH, POLICY AND PRACTICE}

The findings of this study provide a practical insight into the challenges faced by both individuals and facilities during the pandemic. The experiences of respondents have helped to identify areas that were well-resourced and helpful in assisting RACFs in managing patients, as well as areas that require more consideration to better support RACF staff.

These findings can be used and applied by decision-makers on a range of different levels - researchers, aged care providers, local/regional/state health departments and national leaders within government to help inform the development of interventions that may help the sector to recover and cope with ongoing changes i.e. vaccination roll-outs, as well as prepare for potential future outbreaks. Of particular importance are interventions or initiatives that focus on supporting the physical and mental health of staff i.e. those that prevent or minimise worker fatigue and stress. The World Health Organization (WHO) promotes the development of a national pandemic preparedness plan, comprising procedures and protocols that would ensure the consistent provision of resources, essential medicines, and patient management as well as support services and programmes including financial, social and mental health support. ${ }^{17}$ There is potential for future research or policy to consider the development of a tailored RACF-specific plan to prepare the workforce for any future events.

\section{REFERENCES}

1. Adhanom T. WHO Director General's opening remarks at the media briefing on COVID-19 - 11 March 2020. World Health Organization. Geneva. 2020. [cited 2020 April 16] Available from: https://www.who.int/dg/speeches/detail/who-directorgeneral-s-opening-remarks-at-the-media-briefing-on-covid-19--11-march-2020

2. Department of Health. Coro navirus (COVID-19) current situation and case numbers. Commonwealth of Australia. 2020. [cited 2020 May 15] Available from: https://www.health.gov. au/news/health-alerts/novel-coronavirus-2019-ncov-healthalert/coronavirus-covid-19-current-situation-and-case-numbers

3. Mavromaras K, Knight G, Isherwood L, Crettenden A, Flavel J, Karmel T, et al. National Aged Care Workforce Census and Survey - the aged care workforce 2016. Australian Government Department of Health. Canberra. 2017.

4. Australian Nursing and Midwifery Federation (ANMF) - Federal Office. National COVID-19 in Aged Care Survey. Australian Nursing and Midwifery Federation (ANMF) - Federal Office. 2020. [cited 2021 July 22] Available from: http://www.anmf.org. au/documents/reports/ANMFAgedCareCOVID-19Survey2020 FinalReport.pdf

5. Siebenhofer A, Huter S, Avian A, Mergenthal K, SchafflerSchaden D, Spary-Kainz U, et al. COVI-Prim survey: challenges for Austrian and German general practitioners during initial phase of COVID-19. PloS One. 2021; 16(6): e0251736. Available from: https://doi.org/10.1101/2020.11.24.20237743

6. Graneheim UH, Lundman B. Qualitative content analysis in nursing research: concepts, procedures and measures to achieve trustworthiness. Nurse Educ Today 2004; 24(2): 105-12 Available from: https://doi.org/10.1016/j.nedt.2003.10.001

7. Thomas DR. A general inductive approach for qualitative data analysis. Am J Eval. 2006; 27(2): 237-46.

8. Svenningsen $H$, Sørensen D. Hospital and nursing home patients' experiences with delirium assessments: a qualitative content analysis. Nord J Nurs Res 2020; 40(1): 52-8. Available from: https://doi.org/10.1177/2057158519882823

9. Blanco-Donoso LM, Moreno-Jiménez J, Gallego-Alberto L, Amutio A, Moreno-Jimenez B, Garrosa E. Satisfied as professionals, but also exhausted and worried!!! The role of job demands, resources and emotional experiences of Spanish nursing home workers during the COVID-19 pandemic. Health Soc Care Community. 2021; 00: 1-13. Available from: https:// doi.org/10.1111/hsc.13422

10. Sarabia-Cobo C, Pérez V, de Lorena P, Hermosilla Grijalbo C, Saenz-Jalon M, Fernandez-Rodriguez A, et al. Experiences of geriatric nurses in nursing home settings across four countries in the face of the COVID-19 pandemic. J Adv Nurs. 2021; 77(2): 869-78. Available from: https://doi.org/10.1111/jan.14626

11. White EM, Wetle TF, Reddy A, Baier RR. Front-line nursing home staff experiences during the COVID-19 pandemic. J Am Med Dir Assoc 2021; 22(1): 199-203. Available from: https://doi. org/10.1016/j.jamda.2020.11.022

12. Royal Commission into Aged Care Quality and Safety. Residential Care Qquality Indicator Profile. Commonwealth of Australia. Canberra. 2020. Available from: https://agedcare. royalcommission.gov.au/publications/research-paper-15residential-care-quality-indicator-profile 
13. Royal Commission into Aged Care Quality and Safety. Aged care and COVID-19: a special report. Commonwealth of Australia. Canberra. 2020. Available from: https://agedcare. royalcommission.gov.au/publications/aged-care-and-covid-19special-report

14. King's College London. Survey of UK nurses and midwives' highlights their concerns about health, training and workload during COVID-19. King's College London. London. 2020.

Available from: https://www.kcl.ac.uk/news/survey-of-uknurses-and-midwives-highlights-their-concerns-about-healthtraining-and-workload-during-covid-19

15. Australian College of Nursing. The role of registered nurses in residential aged care facilities - Position statement 2016 Australian College of Nursing. [cited 2021 July 8] Available from: https://www.acn.edu.au/wp-content/uploads/positionstatement-role-rn-residential-aged-care-facilities.pdf

16. Aged Care Guide. Duties and responsibilities 2021. Aged Care Guide. [cited 2021 July 12] Available from: https://www. agedcareguide.com.au/information/duties-and-responsibilities

17. World Health Organization. A checklist for pandemic influenza risk and impact management: building capacity for pandemic response. World Health Organization. Geneva. 2018. Available from: https://www.who.int/publications/i/item/9789241513623 